\title{
Tailoring of electrical properties of $\mathrm{BiFeO}_{3}$ by praseodymium
}

\author{
Samita PATTANAYAK, Ashwasa PRIYADARSHAN, Ritesh SUBUDHI, \\ Ranjan Kumar NAYAK, Rajib PADHEE* \\ Department of Physics, Institute of Technical Education \& Research, Siksha 'O' Anusandhan University, \\ Bhubaneswar 751030, India
}

Received: January 05, 2013; Revised: April 10, 2013; Accepted: April 17, 2013

(C) The Author(s) 2013. This article is published with open access at Springerlink.com

\begin{abstract}
The polycrystalline samples of $\mathrm{Bi}_{1-x} \mathrm{Pr}_{x} \mathrm{FeO}_{3}(x=0$ and 0.1$)$ were prepared by a solid-state reaction technique. Preliminary X-ray structural analysis has confirmed the formation of a single-phase compound. Studies of dielectric and impedance spectroscopy of the materials, carried out in wide frequency $(1 \mathrm{kHz}-1 \mathrm{MHz})$ and temperature $\left(25-400{ }^{\circ} \mathrm{C}\right)$ ranges, have provided many interesting results including significant decrement in tangent loss, structural stability, obeying Jonscher's universal power law, etc.
\end{abstract}

Keywords: ceramics; impedance spectroscopy; electrical conductivity

\section{Introduction}

Since the discovery of magnetism in some elements and alloys and ferroelectricity in organic/inorganic compounds, extensive works were carried out with many breakthroughs. Multiferroics is defined as materials which combine at least two "ferroic" properties, such as ferromagnetic order (spontaneous magnetic polarization that can be reversed by a magnetic field), ferroelectricity (e.g., spontaneous electric polarization that can be switched by an applied electric field), and ferroelasticity (change in electric polarization accompanied by a change in shape) [1,2]. Multiferroic compounds are promising candidates for designing emerging electronic devices like multiple-state memories, magnetic data-storage media, actuators, transducers, sensors, and spintronic devices for different technological applications [3,4]. Bismuth ferrite, $\mathrm{BiFeO}_{3}$ (BFO) is the most widely studied

* Corresponding author.

E-mail: padhee4u@gmail.com compound of the family, since it exhibits multiferroicity at room temperature, with a coexistence of ferroelectricity and anti-ferromagnetism up to its Neel temperature of $T_{\mathrm{N}} \approx 643 \mathrm{~K}$ [5]. At room temperature, BFO is a rhombohedrally distorted ferroelectric perovskite with crystallographic space group $R 3 c$ [6]. Its ferroelectric Curie temperature $\left(T_{\mathrm{C}}\right)$ is $1100 \mathrm{~K}$. Unfortunately, BFO has high leakage current, low dielectric constant and high tangent loss [7] that limit the material to be used for fabrication of devices. Above problems can be reduced or eliminated by substituting suitable rare-earth elements or other element(s) at the Bi-site of BFO [8,9]. Even though lots of experimental works have been done on rare-earth ions including praseodymium (Pr)-substituted BFO [10], not much work on resistance and/or impedance properties of the Pr-modified BFO has been done so far. Therefore, in the present work, we report the detailed electrical characterizations of $\mathrm{Bi}_{1-x} \mathrm{Pr}_{x} \mathrm{FeO}_{3}(x=0$ and $0.1, \mathrm{BFO}$ and $\mathrm{BPFO}$ respectively). 


\section{Experiment}

The polycrystalline samples of $\mathrm{Bi}_{1-x} \mathrm{Pr}_{x} \mathrm{FeO}_{3}(x=0$ and $0.1)$ were synthesized by using a high-temperature solid-state reaction technique with high-purity (analytical reagent grade) ingredients: $\mathrm{Bi}_{2} \mathrm{O}_{3}, \mathrm{Pr}_{2} \mathrm{O}_{3}$ and $\mathrm{Fe}_{2} \mathrm{O}_{3}(99.9 \%$, all from M/s LOBA Chemie. Pvt. Ltd., India). These oxides were mechanically mixed in dry (air) and wet (methanol) medium for several hours in an agate mortar. The mixed materials were calcined in the temperature range of $780-810{ }^{\circ} \mathrm{C}$ for $4 \mathrm{~h}$ in an alumina crucible. X-ray diffraction (XRD) patterns of the calcined powders were recorded at room temperature using $\mathrm{X}$-ray powder diffractometer (XRD $6000)$. The $\mathrm{Cu} \mathrm{K} \alpha$ radiation $(\lambda=1.5405 \AA$ ) was used to record the pattern and data in a wide range of Bragg angle $\theta\left(20^{\circ} \leqslant 2 \theta \leqslant 80^{\circ}\right)$ at a scanning rate of $3\left({ }^{\circ}\right) / \mathrm{min}$. Using PVA (binder)-mixed calcined powders, the cylindrical pellets $(10 \mathrm{~mm}$ in diameter and $1-2 \mathrm{~mm}$ in thickness) were fabricated under a uni-axial pressure of $4 \times 10^{6} \mathrm{~N} / \mathrm{m}^{2}$. The pellets were sintered at optimized temperature in the range of $820-850{ }^{\circ} \mathrm{C}$ in air atmosphere for $4 \mathrm{~h}$ to get mechanically stable, strong and high-density $(>95 \%$ of theoretical density) samples. The polished sintered pellets were silvered with high-purity and high-quality silver paste, and dried at $160{ }^{\circ} \mathrm{C}$ for $8 \mathrm{~h}$ before taking dielectric and electrical measurements. The capacitance, dissipative factor and impedance parameters were measured as a function of temperature $\left(25-400{ }^{\circ} \mathrm{C}\right)$ in a wide range of frequency $(1 \mathrm{kHz}-1 \mathrm{MHz})$, using a computer-controlled LCR meter (PSM-4NL Model: 1735, UK) along with a laboratory-designed and fabricated sample holder and furnace. To record the temperature at small interval, a chromel-alumel thermo-couple and KUSAM MECO 108 digital milli-voltmeter were used.

\section{Results and discussion}

\section{1 Structural analysis}

The XRD patterns of $\mathrm{Bi}_{1-x} \mathrm{Pr}_{x} \mathrm{FeO}_{3} \quad(x=0$ and 0.1$)$, recorded at room temperature on their powder samples, are compared in Fig. 1. The XRD patterns consist of many sharp and single peaks, which are different from those of the ingredients. Each XRD pattern clearly exhibits better homogeneity and crystallization of the sample, and thus confirms the formation of new

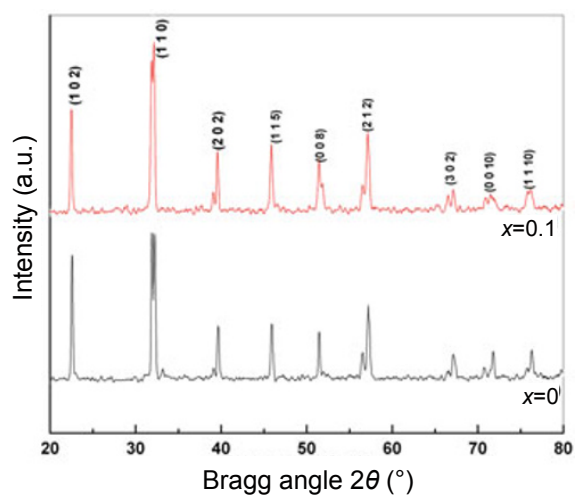

Fig. 1 XRD patterns of $\mathrm{Bi}_{1-x} \mathrm{Pr}_{x} \mathrm{FeO}_{3}(x=0$ and $0.1)$.

compound in a single phase [10]. The reflection peaks are indexed in different unit cell configurations using standard computer software POWDMULT [11], and the lattice parameters of the BPFO ceramics as a function of $\operatorname{Pr}$ content are analyzed. From the best agreement between the observed $\left(d_{\text {obs }}\right)$ and calculated $\left(d_{\text {cal }}\right)$ inter-planner distances $d \quad\left(\Sigma\left(d_{\text {obs }}-d_{\text {cal }}\right)=\right.$ minimum), BPFO is found to be in the rhombohedral crystal system. The cell parameters have been compared in Table 1.

Table 1 Comparison of the cell dimensions of BFO and BPFO

\begin{tabular}{ccccc}
\hline & $a(\AA)$ & $c(\AA)$ & $c / a$ & $V\left(\AA^{3}\right)$ \\
\hline BFO & $5.5706(7)$ & $13.8114(7)$ & 2.4793 & 372.96 \\
BPFO & $5.575(8)$ & $13.585(8)$ & 2.4368 & 365.69 \\
\hline
\end{tabular}

\section{2 Dielectric study}

The variation of relative dielectric constant $\left(\varepsilon_{\mathrm{r}}\right)$ and $\operatorname{tangent} \operatorname{loss}(\tan \delta)$ as a function of temperature at some selected frequencies $(10 \mathrm{kHz}, 100 \mathrm{kHz}$ and $1 \mathrm{MHz})$ is shown in Figs. 2(a) and 2(b). The magnitude of $\varepsilon_{\mathrm{r}}$ increases with rise in temperature. The increase in the value of $\varepsilon_{\mathrm{r}}$ can be ascribed as the electron-phonon interaction [12]. The increase in $\varepsilon_{\mathrm{r}}$ can be understood in terms of the thermally activated transport property and presence of space charges [13]. The dielectric anomaly (related to relaxation) is observed at $270{ }^{\circ} \mathrm{C}$ and it shifts towards higher temperature with increasing $\mathrm{Pr}$ substitution. This relaxation may be due to the anti-ferromagnetic transition [14]. The magnitude of $\varepsilon_{\mathrm{r}}$ in BPFO increases on increasing Pr content which is shown in Fig. 2(c) (at $100 \mathrm{kHz}$ ). This suggests that Pr-substitution has a significant effect on dielectric properties of BPFO. Therefore, substitution of $\mathrm{Pr}$ in BFO has enhanced the dielectric properties. The 

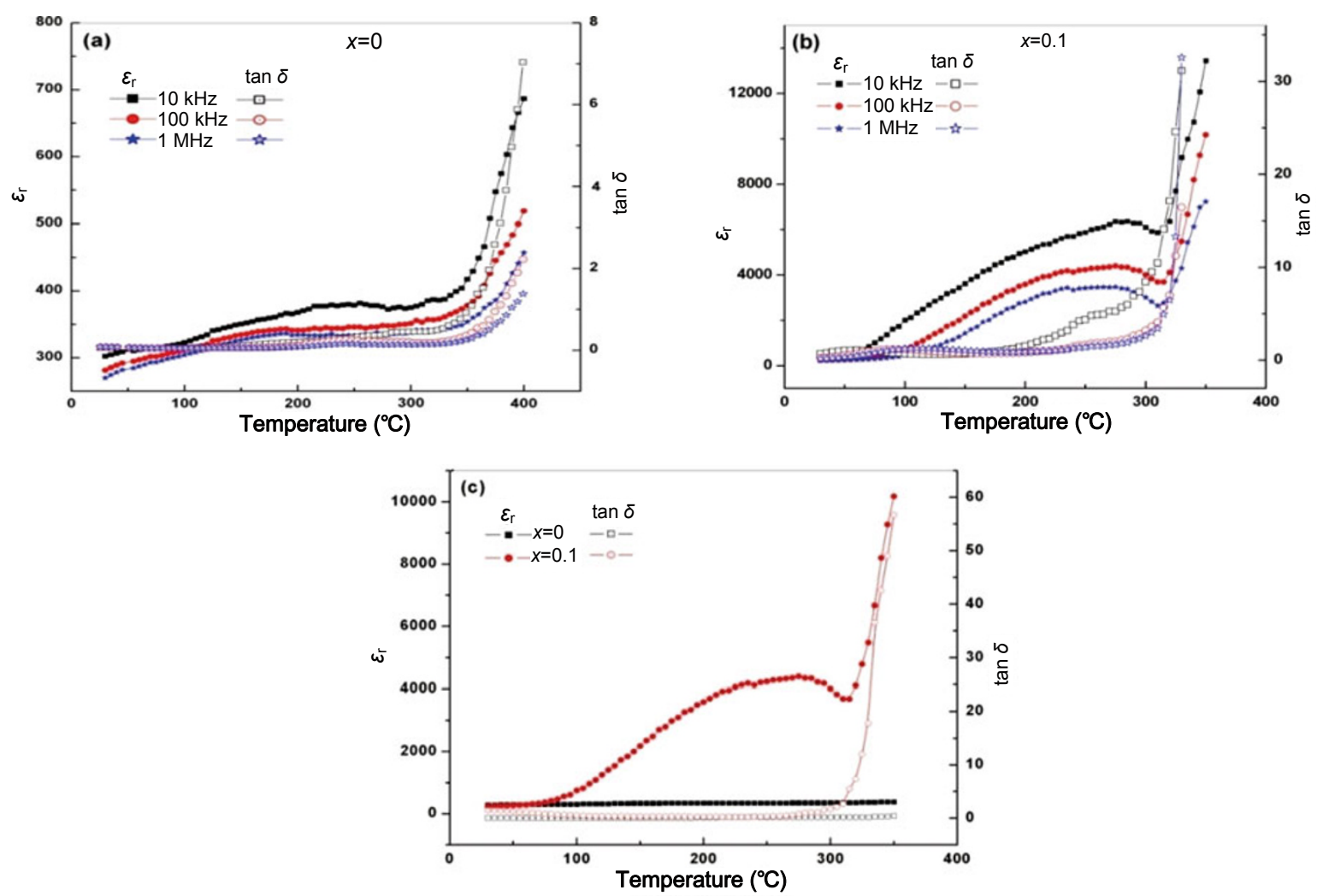

Fig. 2 Variation of $\varepsilon_{\mathrm{r}}$ and $\tan \delta$ of $\mathrm{Bi}_{1-x} \mathrm{Pr}_{x} \mathrm{FeO}_{3}(x=0$ and 0.1$)$ with temperature at different frequencies $(10 \mathrm{kHz}$, $100 \mathrm{kHz}$ and $1 \mathrm{MHz}$ ).

temperature dependence of $\tan \delta$ follows nearly the same trend as $\varepsilon_{\mathrm{r}}$. However, at higher temperatures, $\tan \delta$ value increases very rapidly. This may be the result of (i) scattering of thermally activated charge carriers due to which the charges are deposited near the grain boundary region, that increases $\varepsilon_{\mathrm{r}}$, and (ii) some inherent defects in the samples.

\section{3 Impedance analysis}

Complex impedance spectroscopy (CIS) is a non-destructive, unique and powerful technique to study electrical properties of polycrystalline and ionic materials over a wide range of frequency and temperature. This technique is very useful in separating the contributions of (i) bulk, (ii) grain boundary and (iii) electrode polarization in complex impedance and other related electrical parameters with different equivalent circuits.

For this technique, an AC signal is applied across the pellet sample, and the output response is measured. The impedance parameters of the material give us data having both real (resistive) and imaginary (reactive) components. The basic equations/formalism of impedance and electrical modulus has been used to study impedance spectroscopic parameters of the samples [15].

Figure 3 shows the variation of real part $\left(Z^{\prime}\right)$ and imaginary part $\left(Z^{\prime}\right)$ of impedance with frequency at different temperatures for different concentrations of $\mathrm{Pr}$ in $\mathrm{Bi}_{1-x} \mathrm{Pr}_{x} \mathrm{FeO}_{3}$. The decrease in the magnitude of $Z^{\prime}$ with rise in both temperature and frequency indicates the increase in conductivity of the materials. At higher frequencies, the values of $Z^{\prime}$ coincide with each other, which is due to the possible release of space charges [16]. The frequency at which the magnitude of $Z^{\prime \prime}$ attains a maximum value, is known as relaxation frequency $\left(f_{\mathrm{r}}\right)$. The maximum value of $Z^{\prime \prime}$ decreases with rise in temperature and concentration of Pr, which indicates relaxation in the samples [17]. The broadening of peak with increase of temperature suggests the presence of temperature dependence of relaxation phenomenon in the materials. The relaxation process occurs due to the presence of immobile charges at lower temperatures and defects or vacancies at higher temperatures $[18,19]$. Figure 3(c) shows the effect of Pr concentration on real and imaginary parts of impedance at $300{ }^{\circ} \mathrm{C}$. It is observed that on increasing $\mathrm{Pr}$ content in BPFO, these real impedance 

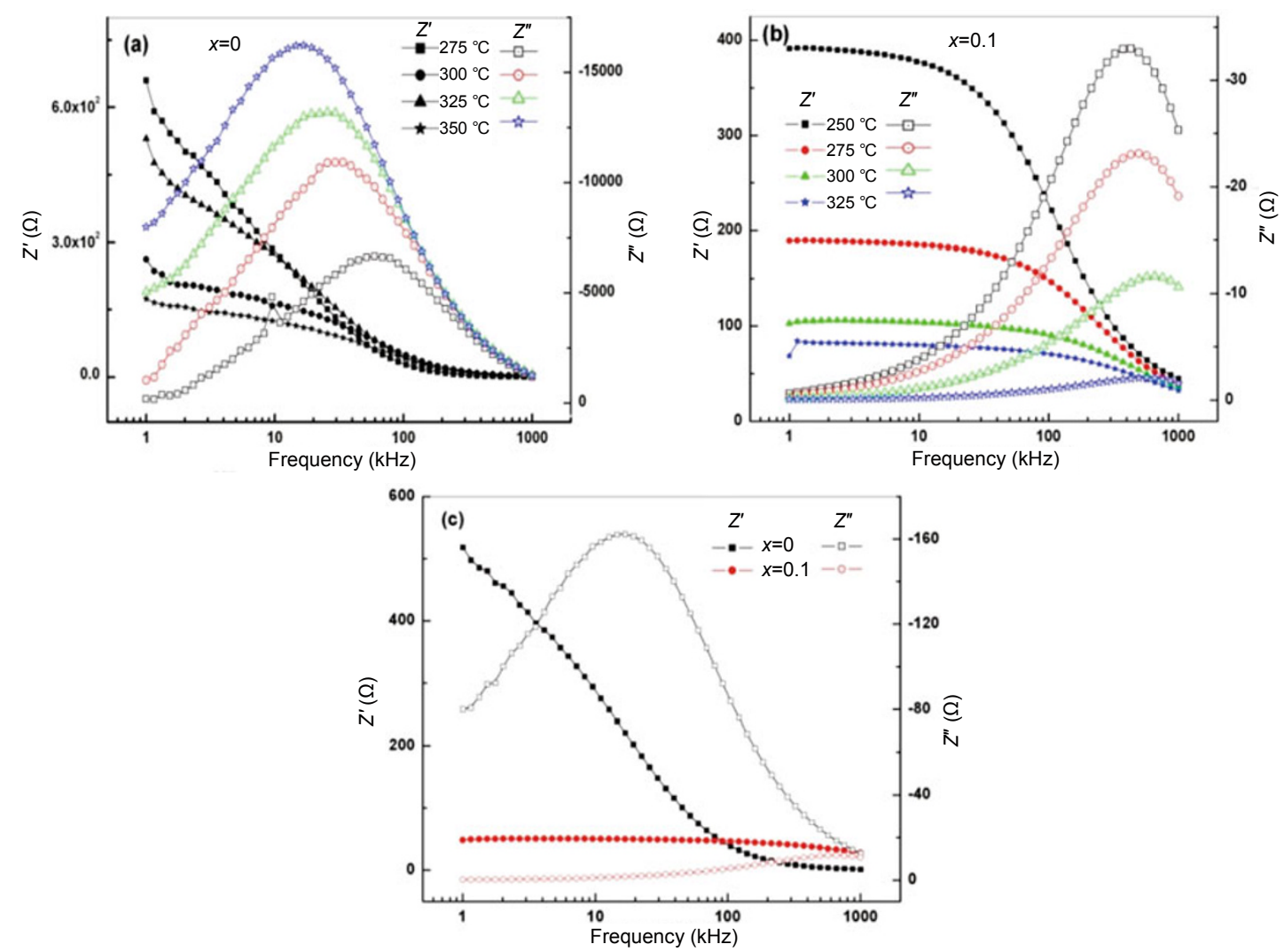

Fig. 3 Variation of $Z^{\prime}$ and $Z^{\prime \prime}$ of $\mathrm{Bi}_{1-x} \mathrm{Pr}_{x} \mathrm{FeO}_{3}(x=0$ and 0.1$)$ with frequency at different temperatures.

parameters significantly decrease, and the imaginary impedance component's peak shifts towards higher-frequency side.

Figure 4 shows the temperature dependence of complex impedance spectra (usually referred as Nyquist plot [20]) over a wide range of frequency $(1 \mathrm{kHz}-1 \mathrm{MHz})$ for $\mathrm{Bi}_{1-x} \mathrm{Pr}_{x} \mathrm{FeO}_{3}(x=0$ and 0.1$)$. At low temperatures, complex impedance plots are single semicircular arc (which is not shown in figure), whereas at higher temperatures $\left(250-325{ }^{\circ} \mathrm{C}\right)$ two semicircular arcs with center below the real axis are observed. The presence of a second semi-circle is due to grain boundary effect in the materials [21]. The plots of Fig. 4 show (real or practical) Debye-like response. An equivalent circuit consists of parallel combination of $\mathrm{CQR}$ and $\mathrm{CR}$, where $\mathrm{Q}$ is called constant phase element (CPE). The presence of non-semicircle indicates the existence of non-Debye type of relaxation in the sample $[22,23]$. For Debye-type relaxation, a semicircle with its center at $Z^{\prime}$ axis is observed. As the value of $\operatorname{Pr}$ content increases, the bulk resistance $\left(R_{\mathrm{b}}\right)$ decreases (Fig. 4(c) at $300{ }^{\circ} \mathrm{C}$ ), which again indicates the increase in conductivity with the increase in $\mathrm{Pr}$ content. However, in the studied materials, we did not get ideal Debye-type relaxation. Thus, depressed small semi-circles indicate non-Debye type of relaxation.

\section{4 AC conductivity}

Figure 5 shows the AC conductivity plots as a function of frequency at different temperatures. The values of $\sigma_{\mathrm{AC}}$ are calculated from dielectric data using an empirical relation: $\sigma_{\mathrm{AC}}=\varepsilon_{0} \varepsilon_{\mathrm{r}} \omega \tan \delta$ [24], where $\varepsilon_{0}, \omega$ and $\tan \delta$ are dielectric permittivity in vacuum, angular frequency and tangent loss, respectively. In the low-frequency region, $\sigma_{\mathrm{AC}}$ remains almost constant (i.e., frequency-independent plateau), whereas the dispersion of conductivity is observed in the higher-frequency region. At higher temperatures, the conductivity curves show frequency-independent plateau in the low-frequency region, whereas at higher frequencies, $\sigma_{\mathrm{AC}} \propto \omega^{n}$. As the Pr-substitution and temperature increase, all the curves tend to flatten at $300{ }^{\circ} \mathrm{C}$ in Fig. 5(c). The flattening is much clearer in low-frequency region, suggesting domination of DC conduction behavior. In the case of Debye model, the value of $n$ is unity [25]. In another case, the motion of charge carriers is translational because of small value 

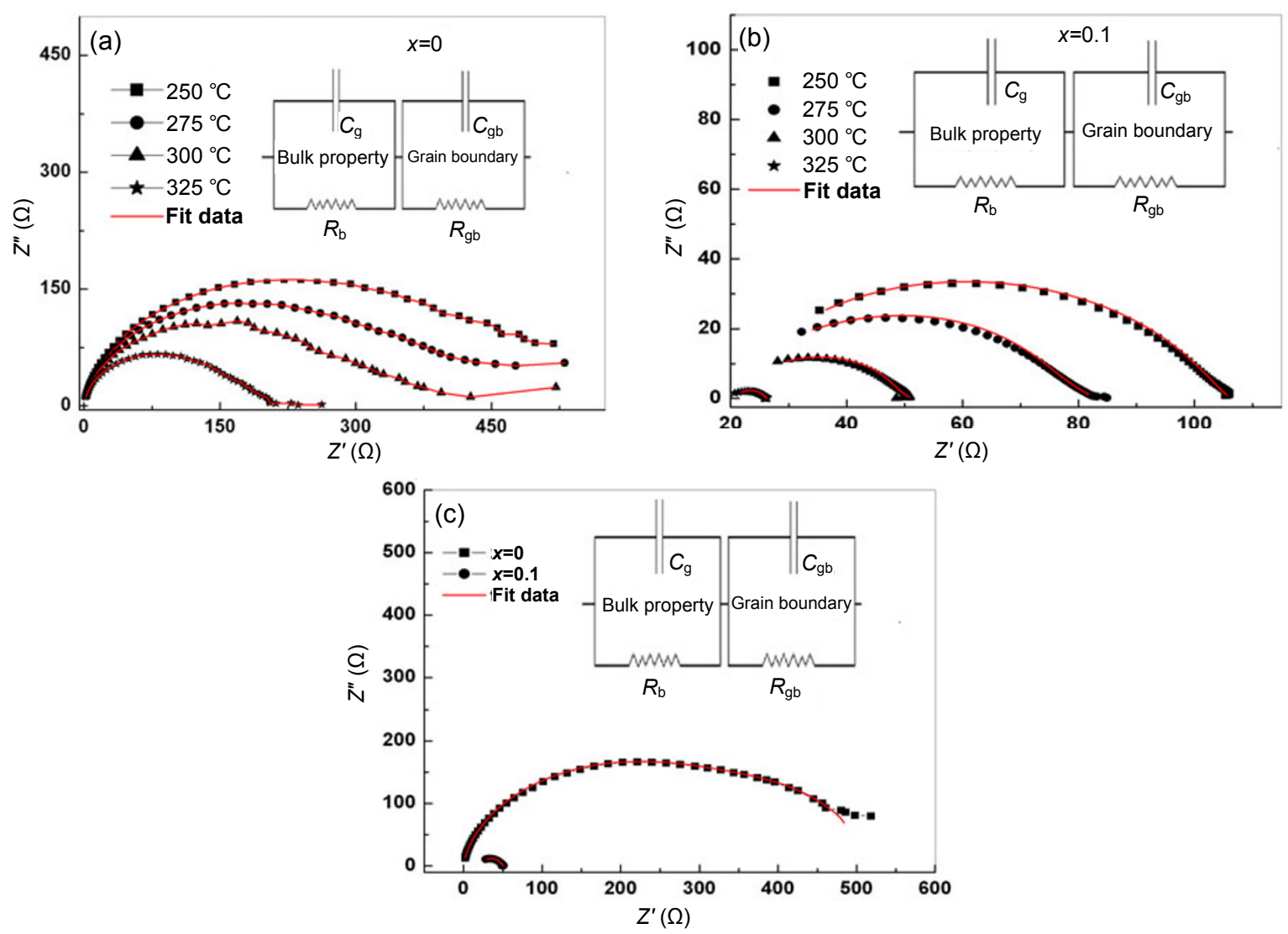

Fig. 4 Variation of $Z^{\prime \prime}$ with $Z^{\prime}$ of $\mathrm{Bi}_{1-x} \mathrm{Pr}_{x} \mathrm{FeO}_{3}(x=0$ and 0.1$)$ at different temperatures.

of $n(<1)$. The value of $n<1$ signifies that the hopping motion involves a translational motion with a sudden hopping, whereas $n>1$ means that the motion involves localized hopping without the species leaving the neighborhood [13].

\section{5 DC conductivity}

Figure 6 shows the variation of DC conductivity $\left(\sigma_{\mathrm{DC}}\right)$ with inverse absolute temperature. It is calculated with the help of a mathematical relation: $\sigma_{\mathrm{DC}}=t /\left(A \cdot R_{\mathrm{b}}\right)$, where $t$ is the thickness of the sample, $A$ is the area of cross section and $R_{\mathrm{b}}$ is the bulk resistance. It is observed that DC conductivity increases with increase in temperature, which further supports the negative temperature coefficient of resistance (NTCR) behavior of the samples. The nature of the plots follows the Arrhenius relation: $\sigma_{\mathrm{DC}}=\sigma_{0} \exp \left[-E_{\mathrm{a}} /(K \cdot T)\right]$ [25]. The slope of the graph gives the activation energy of the material. The calculated values of activation energy are found to be $0.78 \mathrm{eV}$ and $0.69 \mathrm{eV}$ for $x=0$ and 0.1 of $\mathrm{Bi}_{1-x} \mathrm{Pr}_{x} \mathrm{FeO}_{3}$, respectively. The conductivity increases considerably with increasing the Pr substitution.

\section{Conclusions}

The polycrystalline samples of $\mathrm{Bi}_{1-x} \mathrm{Pr}_{x} \mathrm{FeO}_{3}(x=0$ and 0.1 ) were prepared by a standard mixed oxide method. Preliminary structural studies suggest that $\mathrm{Bi}_{1-x} \mathrm{Pr}_{x} \mathrm{FeO}_{3}$ has rhombohedral structure. The dielectric constant is found to be increasing and the tangent loss decreasing at room temperature. The impedance studies exhibit the presence of grain (bulk) and grain boundary effects, and existence of NTCR behavior in the materials. The frequency-dependent electrical conductivity obeys Jonscher's power law, and is in good agreement with real parts of impedance versus frequency plots.

Open Access: This article is distributed under the terms of the Creative Commons Attribution Noncommercial License which permits any noncommercial use, distribution, and reproduction in any medium, provided the original author(s) and source are credited. 

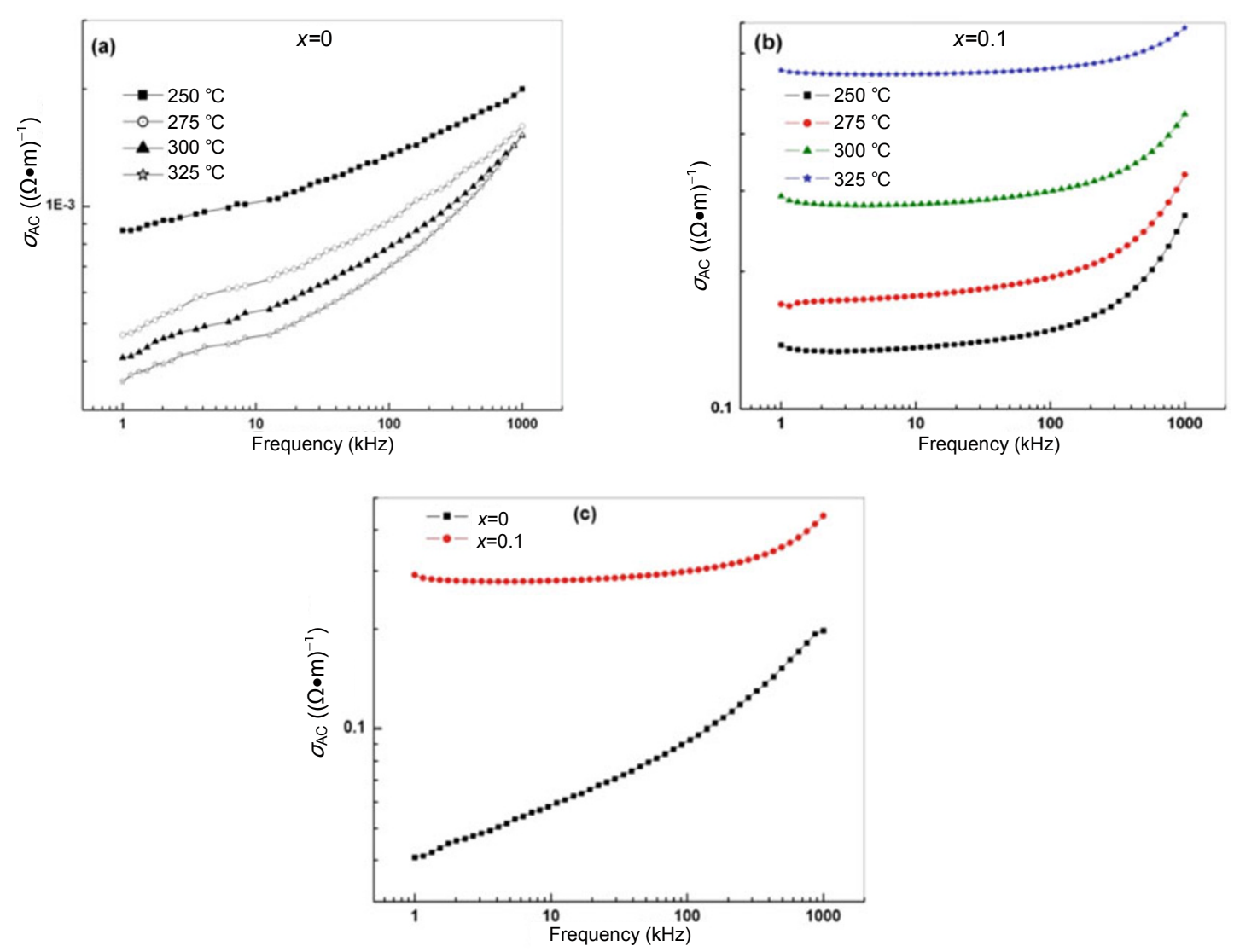

Fig. 5 Variation of $\mathrm{AC}$ conductivity $\left(\sigma_{\mathrm{AC}}\right)$ of $\mathrm{Bi}_{1-x} \mathrm{Pr}_{x} \mathrm{FeO}_{3}(x=0$ and 0.1$)$ with frequency at different temperatures.

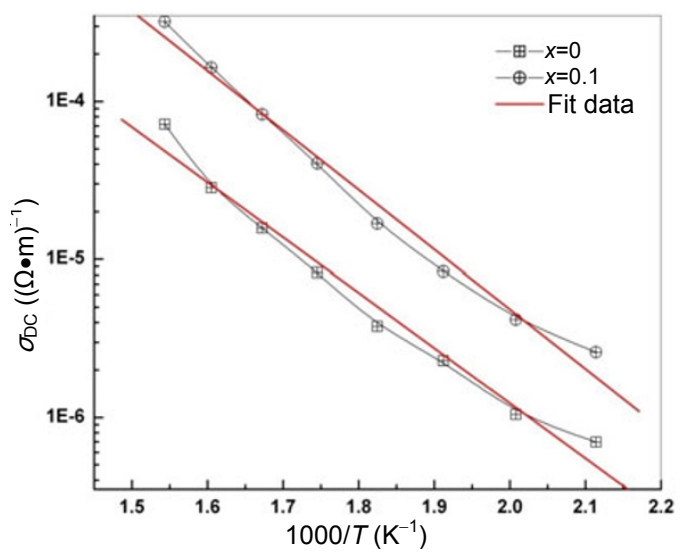

Fig. 6 Variation of DC conductivity of $\mathrm{Bi}_{1-x} \mathrm{Pr}_{x} \mathrm{FeO}_{3}(x=0$ and 0.1$)$ with temperature.

\section{References}

[1] Zhao T, Scholl A, Zavaliche F, et al. Electrical control of antiferromagnetic domains in multiferroic $\mathrm{BiFeO}_{3}$ films at room temperature. Nat Mater 2006, 5: 823-829.

[2] Ramesh R, Spaldin NA. Multiferroics: Progress and prospects in thin films. Nat Mater 2007, 6: 21-29.

[3] Rehspringer J-L, Bursik J, Niznansky D, et al.
Characterisation of bismuth-doped yttrium iron garnet layers prepared by sol-gel process. J Magn Magn Mater 2000, 211: 291-295.

[4] Das R, Khan GG, Mandal K. Enhanced ferroelectric, magnetoelectric, and magnetic properties in $\mathrm{Pr}$ and $\mathrm{Cr}$ co-doped $\mathrm{BiFeO}_{3}$ nanotubes fabricated by template assisted route. J Appl Phys 2012, 111: 104115.

[5] Karimi S, Reaney IM, Han Y, et al. Crystal chemistry and domain structure of rare-earth doped $\mathrm{BiFeO}_{3}$ ceramics. J Mater Sci 2009, 44: 5102-5112.

[6] Michel C, Moreau J-M, Achenbach GD, et al. The atomic structure of $\mathrm{BiFeO}_{3}$. Solid State Commun 1969, 7: 701-704.

[7] Teague JR, Gerson R, James WJ. Dielectric hysteresis in single crystal $\mathrm{BiFeO}_{3}$. Solid State Commun 1970, 8: 1073-1074.

[8] Xu JM, Wang GM, Wang HX. Synthesis and weak ferromagnetism of Dy-doped $\mathrm{BiFeO}_{3}$ powders. Mater Lett 2009, 63: 855-857.

[9] Vopsaroiu M, Cain MG, Sreenivasulu G, et al. Multiferroic composite for combined detection of static and alternating magnetic fields. Mater Lett 2012, 66: 282-284.

[10] Parida BN, Das PR, Padhee R, et al. Synthesis and 
chracterization of a tungsten bronze ferroeletcric oxide. Adv Mat Lett 2012, 3: 231-238.

[11] Wu E. POWDMULT: An interactive powder diffraction data interpretation and indexing program version 2.1. School of Physical Sciences, Flinders University of South Australia, Bradford Park, SA 5042, Australia.

[12] Parida BN, Das PR, Padhee R, et al. Phase transition and conduction mechanism of rare earth based tungsten-bronze compounds. J Alloys Compd 2012, 540: $267-274$.

[13] Barick BK, Mishra KK, Arora AK, et al. Impedance and Raman spectroscopic studies of $\left(\mathrm{Na}_{0.5} \mathrm{Bi}_{0.5}\right) \mathrm{TiO}_{3}$. J Phys D: Appl Phys 2011, 44: 355402.

[14] Nalwa KS, Garg A, Upadhya A. Effect of samarium doping on the properties of solid-state synthesized multiferroic bismuth ferrite. Mater Lett 2008, 62: 878-881.

[15] Parida BN, Das PR, Padhee R, et al. A new ferroelectric oxide $\mathrm{Li}_{2} \mathrm{~Pb}_{2} \mathrm{Pr}_{2} \mathrm{~W}_{2} \mathrm{Ti}_{4} \mathrm{Nb}_{4} \mathrm{O}_{30}$ : Synthesis and characterization. J Phys Chem Solids 2012, 73: 713-719.

[16] Wieczorek W, Płocharski J, Przyłuski J. Impedance spectroscopy and phase structure of PEO NaI complexes. Solid State Ionics 1982, 28-30: 1014-1017.

[17] Behera B, Nayak P, Choudhary RNP. Structural and impedance properties of $\mathrm{KBa}_{2} \mathrm{~V}_{5} \mathrm{O}_{15}$ ceramics. Mater
Res Bull 2008, 43: 401-410.

[18] Jonscher AK. The 'universal' dielectric response. Nature 1977, 267: 673-679.

[19] Suman CK, Prasad K, Choudhary RNP. Complex impedance studies on tungsten-bronze electroceramic: $\mathrm{Pb}_{2} \mathrm{Bi}_{3} \mathrm{LaTi}_{5} \mathrm{O}_{18}$. J Mater Sci 2006, 41: 369-375.

[20] Irvine JTS, Sinclair DC, West AR. Electroceramics: Characterization by impedance spectroscopy. $A d v$ Mater 1990, 2: 132-138.

[21] Macdonald JR. Note on the parameterization of the constant-phase admittance element. Solid State Ionics 1984, 13: 147-149.

[22] Choudhary RNP, Perez K, Bhattachrya P, et al. Structural and electrical properties of $\mathrm{BiFeO}_{3}-\mathrm{Pb}(\mathrm{ZrTi}) \mathrm{O}_{3}$ composites. Appl Phys A 2007, 86: $131-138$.

[23] Pattanayak S, Parida BN, Das PR, et al. Impedance spectroscopy of $\mathrm{Gd}$-doped $\mathrm{BiFeO}_{3}$ multiferroics. Appl Phys A 2012, DOI: 10.1007/s00339-0127412-6.

[24] Barick BK, Choudhary RNP, Pradhan DK. Phase transition and electrical properties of lanthanum-modified sodium bismuth titanate. Mater Chem Phys 2012, 132: 1007-1014.

[25] Shukla A, Choudhary RNP. Study of electrical properties of $\mathrm{La}^{3+} / \mathrm{Mn}^{4+}$-modified $\quad \mathrm{PbTiO}_{3}$ nanoceramics. J Mater Sci 2012, 47: 5074-5085. 